\title{
OPPORTUNITIES OF INTEGRATING DESALINATION TO COGENERATION FOR BRAZILIAN CONDITIONS
}

\begin{abstract}
E. M. Ferreira ${ }^{a}$ ABSTRACT
J. A. P. Balestieri ${ }^{\text {b }}$

M. A. Zanardi

${ }^{a}$ Universidade Estadual Paulista

Av. Dr. Ariberto Pereira da Cunha, 333 12516410 Guaratinguetá, S.P., Brasil.

mfeduardo@uol.com.br

${ }^{\mathrm{b}}$ Universidade Estadual Paulista

Av. Dr. Ariberto Pereira da Cunha, 333 12516410 Guaratinguetá, S.P., Brasil.

perrella@feg.unesp.br

${ }^{\circ}$ Universidade Estadual Paulista

Av. Dr. Ariberto Pereira da Cunha, 333

12516-410 Guaratinguetá, S.P., Brasil mzanardi@feg.unesp.br

One of the major problems in this century refers to the availability of potable water, necessary to the survival of populations. The world population is continually increasing and natural resources are proportionally decreasing, and the development of potable water production techniques demands intensive efforts. Electric power requirement is also necessary to the development of nations. Desalination processes are widely used in countries with low offer of potable water. Technologies nowadays in use are multi-stage-flash distillation (MSF), multi-effect distillation (MED) and reverse osmosis (RO) process. In MSF and MED processes, the main technique is distillation. Reverse osmosis technique relies on the osmotic principle, in which a solvent passes through a membrane. Since the middle of 1950, these desalting techniques are widely used mainly in the Middle East countries, where water shortage is almost absolute. Although uncommonly conceived, discussing the implementation of desalination processes in association to cogeneration systems in Brazil is a necessary task for the long-term planning. In this way, this paper proposes to review the successful experiences presented in the literature as a way of establishing how electric power and fresh water production can be produced from seawater desalting processes in an optimized way. Another objective pursued in this paper is stimulating more attention to this matter, that deserves discussing the skill staff formation and the know-how of such technologies in the strategic planning to the water resource management, specially because these investments require a considerable time for human resources development and the knowledge of the most adequate technology to be implemented for the integration of desalting and cogeneration units.

Keywords: desalination, cogeneration, natural resources planning
\end{abstract}

\section{INTRODUCTION}

Water is a natural resource of first necessity for the existence of any form of life. Human being needs the water consumption to live, for drinking, sanitation and personal hygiene. Other very important resource for the world population is the electric energy, whose generation is nowadays based on hydroelectric plants or in nuclear, coal or natural gas based thermal plants.

Beyond the existing problems in many places with respect to the water scarcity, the reality of supplying systems in some country regions and other parts of the world faces several difficulties. Water availability is not enough in every place and every time, so it does not attend the population needs. On the other hand, water distribution may be also inefficient, due to losses through leaks, lack of maintenance and the misuse, with flagrant wastes. According to Graça (2004), Brazilian water wastes, relatively to the water produced, reach to $46 \%$, that it is equivalent to 5.8 billion of $\mathrm{m}^{3}$ per year. In Europe, this index is around $10 \%$ and $6 \%$ in Cingapura.

The waste of electric energy consumption is about $15 \%$ of all generated energy, equivalent to the Brazilian nuclear power station Angra 2 production. Several researchers report that approximately $0.8 \%$ of the available water in the world is in the form of fresh water (including treatment and sewer stations reuse water), 2.2\% are in the glaciers and $97 \%$ is formed of salty water. Brazil withholds $12 \%$ of the world fresh water, according to UNIAGUA (2003). Because of this, in a first moment, a study that deals with evaluation of the conditions for the desalination technologies utilization in Brazil can be seen as an exceptional fact, especially if it is considered that, comparatively to other countries, Brazil has exceptional hydrologic resources and the practice of cogeneration is not significant for the Brazilian energy sector.
In terms of energy planning of the natural resources, however, it is the correct time to start studies directed to the question of the drinking water availability in the near future, as well as the possibilities of assuring its production and the generation of electric energy, in time to enable human resources to attend future demands, besides establishing the preliminary conditions to medium and long term decisions that will be necessary.

This article presents the worldwide used seawater desalination methods multistage flash distillation (MSF), multi-effect distillation (MED) and reverse osmosis (RO) in association to the cogeneration schemes, which will be useful to generate the energy required by the desalination processes and, perhaps, the generation of electric energy for commercialization.

The application of the cogeneration/desalination integration in Brazil is also discussed based on the drinking water and electricity increasing demands and the problem of modeling must contemplate the possible alternatives in a scientific way. Also, the proposal of integrating desalination and cogeneration units must be faced as a possible alternative, fitting technical, logistic and economic analysis to establish the more adequate conditions for being implemented.

\section{COGENERATION APPLIED TO DESALINATION}

Cogeneration is based on the exploitation of multiple energy forms from the same primary energy. In general, a cogeneration system produces energy in electrical/mechanical or thermal form (steam, water and/or hot and/or cooled air), and the economic attractiveness of enterprises like this will depend on the analysis of the structure of the involved costs in the production of such products. 
When in association with desalination systems, the involved products are, in the most of the cases, electric energy and water with a degree of acceptable potability relatively to certain standards, and steam and/or cooling are equally desirable products. The potability of the water is defined from standards established by Regulating Agencies. In the Brazilian case, the demandable characteristics and the maximum mineral contents allowed in its composition must be in accordance with Decree MS 518 12-00, published in 25/03/2004.

For composing a cogeneration system, consider a process that demands energy in thermal and electromechanical forms, denoted as S and E, respectively, in Fig. 1, shown by Balestieri (2002). The project of a cogeneration system to be associated to the process unit will have to be designed to generate part or all the thermal and electromechanical energy demanded by the unit (S' and $E^{\prime}$ are, respectively, the thermal and electromechanical energy produced by the cogeneration system).

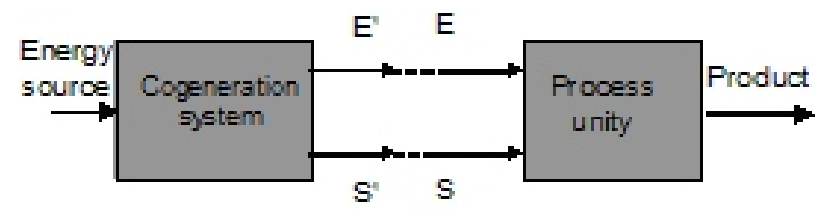

Figure 1. Structure between cogeneration system and process unity

The harmonization between the parcels $\mathrm{E}$ and $\mathrm{E}^{\prime}$, as well as $\mathrm{S}$ and $\mathrm{S}^{\prime}$, depends on the strategies that are conceived for the cogeneration system design. Thus, a project with thermal parity is that in which the equality of the $\mathrm{S}$ and $\mathrm{S}$ ' are imposed, implicating that the production and the consumption of thermal energy must be equal, and the other parcel of generated energy (E') will not necessarily be equal to $\mathrm{E}$ and, in this case, the electric energy purchasing or selling hypothesis must be analyzed. Similar analysis must be done when the electric parity is more adequate.

Cogeneration systems may be associated with desalination units based on the necessity that these processes present relatively to thermal and/or electric energy, which varies as a function of the considered desalination technology. The analysis of energy loads of the process unit must take into account the daily and seasonal energy variability, as well as load fluctuations characteristics, batch or continuous processing, market influences, among others.

The decision concerning to the best scheme to be used, as well as the analysis of the dispatch and coordination of the cogeneration system operation associated with a desalination process, involves certain complexity according to Barclay (1988). In the case of a reduced winter electricity demand, certain associated technologies could present a significant reduction of low cost steam for the drinking water production. For example, a combined unit that presents low electricity to produced water ratio, even with low efficiency, must be operated to satisfy the water demand.

A cogeneration system can be designed based on consolidated technologies, such as steam and gas thermal cycles, as well as to consider advanced technologies. The energy sources for the cogeneration system can be derived from fossils fuels (as natural gas or combustible oil) or renewable (as in natura or gasified biomass). Technologies that have been used in cogenerationdesalination systems according to Azoury (2001) and El-Nashar (2001), are:

- Steam cycle, with conventional boilers and backpressure turbines (CCONV + TVCP);

- Steam cycle, with conventional boilers and condensation and extraction turbines (CCONV + TVCD-E);

- Gas cycle, with gas turbines and heat recovery steam generators (TG + CREC);

- Combined cycles, composed by gas turbines, heat recovery steam generators and back-pressure turbines (CC/TVCP);

- Combined cycles, composed by gas turbines, heat recovery boilers and condensation and extraction turbines (CC/TVCD-E).

\section{DESALINATION PROCESSES}

As it is verified for the cogeneration systems, desalination processes present consolidated technologies. These technologies are nowadays employed in countries where the water scarcity is great, sometimes total; there are desalination processes that still are, at the moment, in diverse stages of development, occupying the bound knowledge. The main processes of desalination currently used are:

- Multi-effect distillation(MED)

- Multistage flash distillation of steam (MSF);

- Reverse osmosis (RO).

According to Van der Bruggen and Vandecasteele (2002), MED process was one of the pioneers in this area. Multiple effects distillation is based on the utilization of condensing steam for heating seawater in a series of stages or effects. In the first effect, the preheated water condenses primary steam. The remaining steam passes to a second stage in a fewer pressure and temperature, and the condensed steam returns to the steam generator. Distillers can be horizontal or vertical. MED plant problems are associated to corrosion and scaling by the presence of $\mathrm{CaSO}_{4}$. Advantage of its use is associated to the high water production rate compared to the steam consumption.

The MSF is based on a series of chambers where steam is generated by the feeding water. The steam is condensed by the exchange of heat in a series of closed pipes where seawater is preheated. Collecting trays are used to collect the condensed water and the resultant brine is re-circulated to increase the water recovery. Its main advantage is the process reliability.

Inorganic compounds precipitation can occur and its reduction is made through acid or anti-scaling, as well as biocides to decrease the bacteria risk. The produced water presents about $50 \mathrm{ppm}$ of total dissolved salts (TDS). The main disadvantage of MSF technology is its performance rate, of approximately $11: 1$, resulting in high energy consumption. However, sometimes this process is economically feasible, as showed by Van Der Bruggen and Vandecasteele (2002).

Although reverse osmosis is known and already applied 50 years ago, only in the 1980s it became competitive in comparison to the distillation techniques. Reverse osmosis is a membrane separation process, in which seawater passes through the membrane by means of an external pressure higher than the osmotic pressure. Pure water produced is named permeate, and the concentrate fraction is named concentrated or brine. The majorities of the membranes are polymeric and consist of a separation thin layer and support layers. Even with a higher pumping 


\section{Tecnologia/Technology}

cost, the produced water cost by $\mathrm{RO}$, around $0.50-0.70$ $\mathrm{US} \$ / \mathrm{m}^{3}$, is half of those achieved by MSF and MED, with a good permeate quality. The disadvantages of RO consist in the membrane sensitivity relative to its scaling and the damage by oxidized compounds, that impose a pretreatment to guarantee a stable module performance, as cited for Van Der Bruggen and Vandecasteele (2002).

Other processes that are still under development or present reduced practical use at this moment are:

- Electro-Dialysis (ED) and reverse electro-dialysis (EDR), which are only feasible for brackish waters or with low salt concentration;

- Steam Compression(VC), used for small installations.

- Solar desalination, which still is considered not economically viable because of its low conversion.

It can be perceived, moreover, that even though the authors defend their methods as the most efficient and of lesser costs, some environment impacts are consequent to the desalination process, which must be considered in a comparative analysis, as seen in Morton, Callister and Wade (1996). The comparison of desalination processes must take into account investment costs, specific energy consumption and the consequent environmental impacts relative to their use.

Applegate (1984) presents energy specific consumption value zones for drinking water production: electrodialysis points out in the range of 1.6 to $2.6 \mathrm{kWh} / \mathrm{m}^{3}$; reverse osmosis varies from 1.6 to $2.1 \mathrm{kWh} / \mathrm{m}^{3}$ for brackish water and from 9.2 to $10.6 \mathrm{kWh} / \mathrm{m}^{3}$ for seawater; ultrafiltration varies from 0.5 to $20 \mathrm{kWh} / \mathrm{m}^{3}$, depending on the use; systems with distillation consumes $43.3 \mathrm{kWh} / \mathrm{m}^{3}$ of produced water, according to Maldonado (1991).

Applegate (1984) describes several membrane separation processes, as well as membrane types, RO devices, pretreatment, and application, economics and the future of some membrane processes, as reverse osmosis, electrodialysis and ultrafiltration.

Maldonado's (1991) review completes Applegate's data, so micro and nanofiltration, dialysis, pervaporation and gas permeation are also studied. It also presents international and national perspectives. Semiat (2000) presents comparative costs, shown in Tab. 1, for the different desalination techniques described in his study, using the data of publications or proposals available at that time. Some general cases are presented. The differences of produced water cost are visible in comparison to distillation methods, mainly the steam flash, steam compression and reverse osmosis methods. The cost range depends mainly on the plant capacity. The values are representative of the application of the technologies in countries with great constraints of drinking water availability.

Several research reports established costs for associated cogeneration desalination systems, and order values of $0.47 \mathrm{US} \$ / \mathrm{m}^{3}$ for MED and $0.86 \mathrm{US} \$ / \mathrm{m}^{3}$ for MSF associated to a $120 \mathrm{MW}$ cogeneration units, or 0.64 and $1.01 \mathrm{US} \$ \mathrm{~m}^{3}$, respectively, for association to a $30 \mathrm{MW}$ cogeneration system are described by Safi and Korchani (1999). Such values had been based on traditional economic methods, and not in the exergoeconomic analysis, and describe other countries reality.

A preliminary study of water costs for Brazilian public services reveals values close to those presented in literature for different desalination technologies. Table 2 presents values for the state service and an autonomous service of water and sewer of São Paulo State. It must be detached that values presented for Tab. 1 refer to the costs
Ferreira, Balestieri and Zanardi et al. Opportunities of ...

of drinking water production and the values described in Tab. 2 correspond to the practiced actual values, and therefore, affected by taxes and tributes.

A distribution of costs as shown by Semiat (2000) is presented in Fig. 2, for which the main osmosis unit costs are related to electric power consumption. Poulikkas (2001) applies another systematic of costs for desalination reverse osmosis, which is given in Tab. 3. Carvalho (2000) demonstrates that reverse osmosis was, for the 1991 data, the more used methodology in worldwide level, as showed, comparatively to the other methods, in Fig. 3. For the energy consumption point of view, the reverse osmosis presents the lowest consumption, as verified in Fig. 4.

Table 1. Desalination cost comparison

\begin{tabular}{|c|c|c|c|c|}
\hline & MSF & MED & VC & RO \\
\hline Installation & $1200-$ & $900-$ & $950-$ & $700-$ \\
$\left(\mathrm{US} \$ / \mathrm{m}^{3} /\right.$ day) & 1500 & 1000 & 1000 & 1000 \\
\hline Product & $1.10-$ & $0.75-$ & $0.87-$ & $0.68-$ \\
$\left(\mathrm{US} \$ / \mathrm{m}^{3}\right)$ & 1.25 & 0.85 & 0.95 & 0.92 \\
\hline
\end{tabular}

Figure 2. Seawater reverses osmosis typical costs

The association of solar energy with desalination processes has been explored for some research groups. Distinct values of water production for a square meter of solar panel are available in the literature. For example, Van der Bruggen and Vandecasteele (2002) report $3.01 / \mathrm{m}^{2}$. For Semiat (2000), $250 \mathrm{~m}^{2}$ of solar collectors is required to the production of $1 \mathrm{~m}^{3}$ of fresh water. In this way, Carvalho (2000) assures that the use of photovoltaic panels for desalination is just feasible in regions in which there is no electric energy supply available and the drinking water consumption is less than $12 \mathrm{~m}^{3} /$ day.

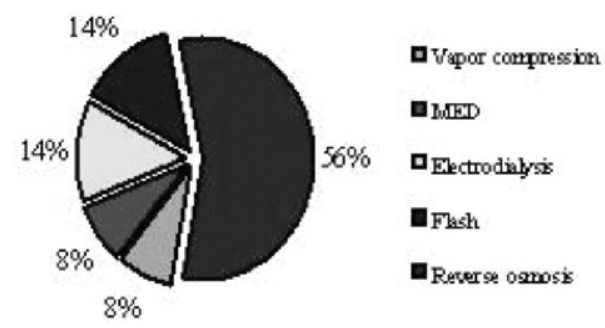

Figure 3. Comparative use of desalination methods

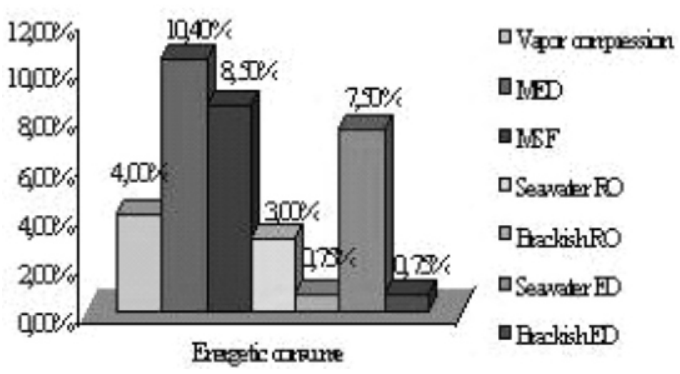

Figure 4. Energetic consume ( $\mathrm{kg}$ oil $/ \mathrm{m}^{3}$ of purified water) 
Ferreira, Balestieri and Zanardi et al. Opportunities of ...

treatment eventually realized by these techniques. An economic comparison among MSF units and a graphical representation of a unit is also presented, in which reverse osmosis presents better investment cost. The author also lists some differences between RO and MSF, as described in the Tab. 5

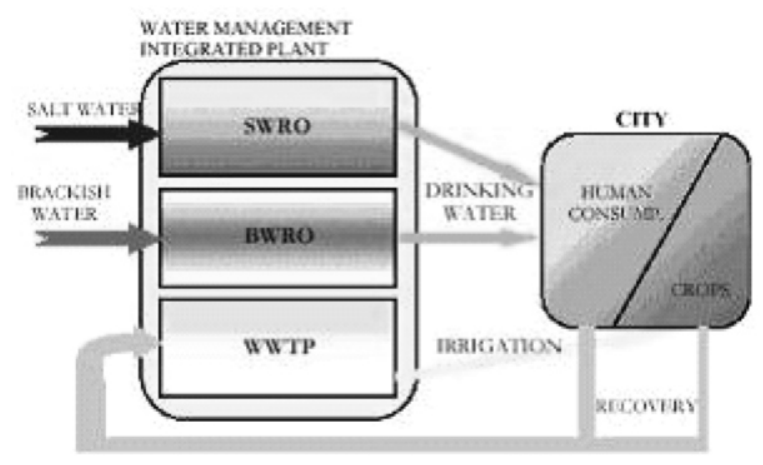

Figure 5. Scheme of the water demand management

The focus of the main studies involving desalination systems, with or without integrated cogeneration, is the production cost of produced drinking water cubic meter and/or the total cost as a function of the installation capacity for a fastest payback. In order to have reliable results in these analyses, several factors must be taken into account, such as the process efficiency, the choice of the thermal cycle and the individual capacity of the machines, the used fuel, the types and options of preand post-treatment, among others, and also, different methodological approaches must be considered.

Table 5. RO and MSF technical differences

\begin{tabular}{|c|c|c|}
\hline \multirow{2}{*}{} & \multicolumn{2}{|c|}{ Magnitude comparisons } \\
\hline Characteristics & MSF to RO & RO to MSF \\
\hline Seawater intake & Twice & ---- \\
\hline $\begin{array}{c}\text { Energy } \\
\text { consumption } / \mathrm{m}^{3}\end{array}$ & Three times & ---- \\
\hline $\begin{array}{c}\text { Volume and area } \\
\text { required }\end{array}$ & Large & ---- \\
\hline Foundation & Heavy & ---- \\
\hline $\begin{array}{c}\text { Thermal energy } \\
\text { consumption }\end{array}$ & $89 \mathrm{MW}(6 \mathrm{mgd})$ & ---- \\
\hline Pumping energy & ---- & $25 \%$ \\
\hline
\end{tabular}

Mathematical optimization models and thermoeconomic models are the most recommended for the analysis of desalination processes feasibility. Poulikkas (2001) proposes an optimization algorithm for the calculation of the drinking water unitary cost. Such algorithm is applied to some configurations of reverse osmosis. As an optimization algorithm, its objective is to find a solution that leads to the minimum global installation cost that corresponds to the annualized investment cost sum of the energy cost, operational and maintenance specific cost, membrane replacement costs and the cost of the chemical products used in the system operation. The author also presents typical ranges of desalinated water production cost of the main components, such as in Tab. 6.
Table 6. Desalinated water production cost range

\begin{tabular}{|c|c|}
\hline Component & Contribution, \% \\
\hline Capital recovery cost & $30-50$ \\
\hline Energy cost & $30-50$ \\
\hline $\begin{array}{c}\text { O \& M (labor, spares, } \\
\text { membranes, chemicals, etc...) }\end{array}$ & $15-30$ \\
\hline
\end{tabular}

Hajeeh et. al. (2003) develops an optimization model in a dual purpose unit with desalination based on distillation, which presents an objective function subjected to the constraints regarding energy generation, load and water supply, among others. This optimization problem is a mixed-integer nonlinear minimization problem.

Helal et. al. (2003) analyzes RO-MSF hybrid units for the determination of an optimum project. The study is divided in 3 papers, the first one devoted to the development of modeling and algorithms. The case studies are presented for:

a- a MSF unit with brine recycle.

b- a RO unit of seawater.

c- Seven hybrid MSF-RO units, with variations in the equipment layout and flows.

Mass and enthalpy balance of the related project sections, as well as the formulation of pertinent heat transference of each section, are presented. The formulation is initially formulated for the cases (a) and (b) and, later, adjusted specifically for the cases of the item (c).

In the second paper, Helal et al. (2004) elaborate the discussion and results of their analysis showing that the adoption of RO units is highly recommended and specially if coupled to an MSF installation it can reduce the water costs in up to $24 \%$. The third part of this study treats the results by means of sensitivity analyses with variations in the component costs and in operational conditions, but it was not published yet and hence not available for consultations on-line.

\section{TECHNOLOGIES INTEGRATION OPPORTUNITIES}

The integration of desalination and cogeneration technologies is particularly important considering that cogeneration systems may supply the necessary energy for operating desalination units, either by means of the steam production in the distillation units or by electricity for water pumping to overcome the osmotic pressure of the reverse system. The associated drinking water production to the generation of electric energy can warranty the attractiveness of this enterprise.

The use of different fuels and multiple cogeneration systems configurations associated with different desalination technologies allows a sufficiently diverse arrangement universe that extends the possibilities of alternative solutions with adequate costs and environmental advantages for the combined generation of electricity and drinking water. In this way, the availability of superstructures or project modules, as proposed in Balestieri and Correia (1997) and Silva et al. (2002), would be very useful for the component selection of the installation in the conceptual phase of design optimization modeling. Figure 6 illustrates a superstructure proposed to link the three systems.

There are many studies, presented in the literature, related to the desalination/cogeneration field, with differentiated level of details, whose objectives are the electric and drinking water production and, mainly, 


\section{Tecnologia/Technology}

reduction in the produced water cost. As the cogeneration system produce two or more products, one suitable partition of costs can make possible achievements that dedicate to offer electricity and drinking water at reasonable prices.

The existence of more than one form of available energy as product of a cogeneration system allows to their costs to be balanced in accordance to the conveniences of the market; thus, electric energy and drinking water prices, in an associated desalination/cogeneration system, will have to be situated in a contract range, as seen in Fig. 7, in which they will oscillate mainly to attend the requirements of demand increases for one or other form of energy in
Ferreira, Balestieri and Zanardi et al. Opportunities of ...

function of the market conditions.

According to Verbruggen (1983), assuming the marginal costs to the electric and thermal energies production are known, a straight line of negative angular coefficient can be gotten if two points, $A$ and $B$, have been chosen, corresponding respectively to the purely electric $\left(\mathrm{CC}_{\mathrm{A}} / \mathrm{E}\right)$ and purely thermal $\left(\mathrm{CC}_{\mathrm{B}} / \mathrm{Q}\right)$ marginal costs, allowing in that way an infinity number of alternatives of costs partition for the combined generation. Some authors consider that the allocation costs rule for combined generated energies must be arbitrary; there is, however, a trend in terms of the use of exergoeconomic models for the costs partition.

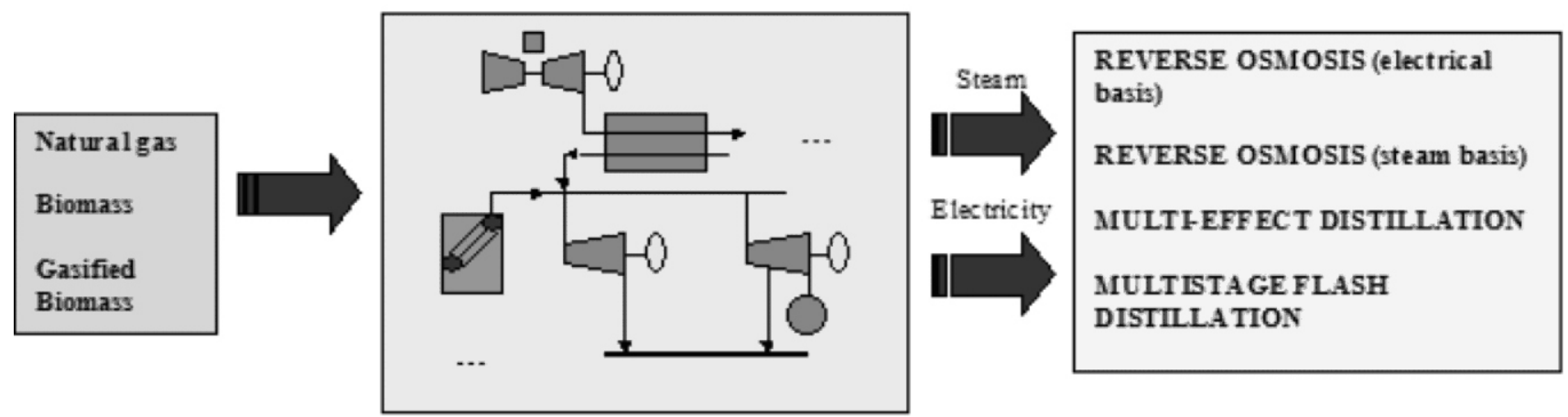

Figure 6. Superstructure for the association cogeneration and desalination technologies

The operational strategy of integrated desalination/cogeneration systems must take in account the seasonal characteristics of the siting facility, that impose in summer periods huge demands for drinking water and electricity (associated to the use of air conditioning systems). As described by Barclay (1988), "in combined water and electricity systems, unit commitment theory is more complex than in electricity only systems. For example, a station with a relatively low electricity/water ratio inevitably has a low efficiency, but must be operated because the water demand must be satisfied. Moreover, the use of exergy theory is essential in order to characterize the thermal performance of the plant and to separate the water and electricity costs."

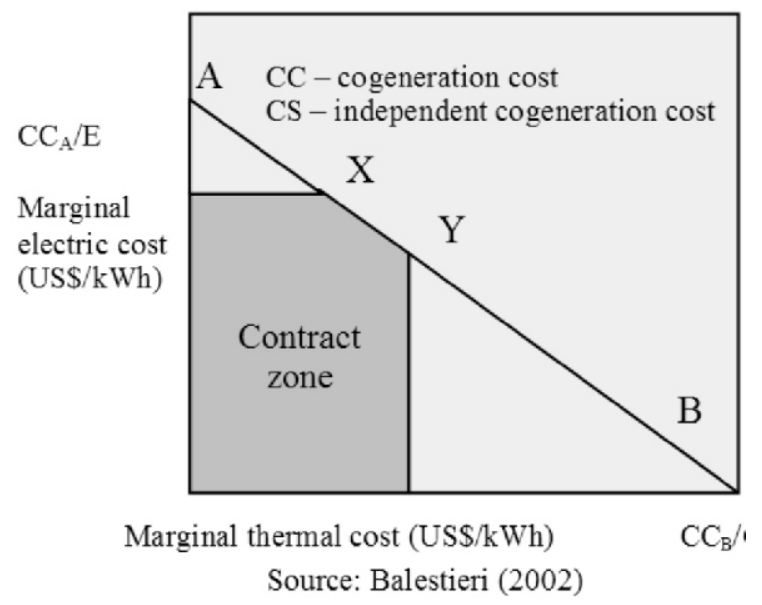

Figure 7. Electrical and thermal marginal costs plane
Coastal cities are particularly affected by problems of water and electricity supply in the summer periods, when the tourist presence raises from 3 to 4 times the number of inhabitants of certain localities; however, in three-quarter of the year, the attendance of the same demands is enough. For these situations, the operational strategy must consider the possibility of using a set of components electrically driven (when this form of energy surpasses the demand) and/or a set of steam driven systems (in the remainder moments), such as described by Altman (1997).

The cogeneration concept considered by Altman (1997) considers the association of electric (ROE) and steam driven (ROS) reverse osmosis systems, whose prime movers are steam turbines; this type of installation provides good flexibility relatively to the demand of drinking water and energy, and the economic analysis presented in the same reference reveals a reduction in the range of $1520 \%$ in the water production costs for ROE when compared with MSF units with cogeneration. The possibilities of bottling the drinking water, generated by desalination processes, for future commercialization, mainly in the months of high demands, must be considered, as well as the transportation and selling of electricity for the concessionaire, as alternatives to achieve the economic feasibility of this enterprise.

\section{CONCLUSIONS}

The decision concerning the use of cogeneration systems in Brazil was contained, on the part of the entrepreneurs, up to the time that an extreme situation, "the 2001 blackout", evidenced the serious structural problems that the Brazilian electrical system was displayed during many years. 


\section{Tecnologia/Technology}

In the current conjuncture, the productive sector uses electricity offered by the concessionaires, but grows the company's number that are investing to analyze the economic viability of this kind of system.

Up to the moment, the question of the water supply follows similar way, with the favorable distinction that the moment of occurrence of the crisis of water supply for absolute lack of this natural resources is yet far from now, and can be foreseen in a space of time of one or two decades. The concepts of a long term strategic planning suggest that, if anticipated in 10 to 15 years, the alternatives for the pinch in the offer and demand of the future scenarios can be established and the problem can be overcome; therefore, it is important to contemplate just now the integration of desalination and cogeneration systems processes in its economic and technical aspects.

Strategic analysis and simulations will reveal the best alternatives for Brazilian conditions; however, it can be seen that configurations that include the reverse osmosis system (RO) in its structure and distillation/reverse osmosis hybrid unit (MSF-RO), mainly in preexistent units that will be adjusted to the new technologies, must be considered as the preliminary schemes. Moreover, the levels of practiced costs in the international market for the established technologies of desalination reveal that there are opportunities to be considered, and it is important to analyze the feasibility of the integration of desalination cogeneration systems processes according to the national standards.

For the analysis of integration between desalination processes and cogeneration systems, the use of an optimization model in a superstructure for the optimization of arrangement selection between components is recommendable, aiming to maximize the net benefit of the investment, taking environmental limits as constraints for the decision process. The use of exergoeconomic modeling has been considered in literature as the most recommendable for the evaluation of the suitable partition of costs between the desalinated water and electricity in cogeneration central and must be considered in the sequence of this work.

\section{REFERENCES}

Al-Mutaz, I. S., 1996, A comparative study of RO and MSF desalination plants, Desalination Vol. 106, pp. 99106.

Altmann, T., 1997, A new power and water cogeneration concept with the application of reverse osmosis desalination, Desalination Vol. 114, pp. 139144.

Applegate, L. E., 1984, Membrane separation processes, Chemical Engineering, Vol. 91, No. 12, pp. 6489, 1984.

Azoury, P. H., 2001, Power and desalination in the Arabian Gulf region: an overview. Proc. Instn. Mechanical Engineers, Vol. 215, Part A, pp. 405-419.

Balestieri, J. A. P., 2002, Cogeração geração combinada de eletricidade e calor, Editora da UFSC, Florianópolis, Santa Catarina.

Balestieri, J. A. P., and Correia, P. B., 1997, Multiobjective linear model for pre-feasibility designs of cogeneration systems, Energy, Vol .22, No.5, pp.537 - 548.

Barclay, F. J., 1988, Cogeneration in arid and cool climates: a new unified perspective using exergy analysis. Journal of Power and Energy Proceedings of the Institution of Mechanical Engineers Vol. 202, No. A2, pp. 129139.
Ferreira, Balestieri and Zanardi et al. Opportunities of ...

Carvalho, P., 2000, Água potável via energia solar, Ciência Hoje, Vol. 27, No. 158, pp. 7274.

El-Nashar, A. M., 2001, Cogeneration for power and desalination - state of the art review, Desalination, Vol. 134, pp. 7-28.

Graça, A., 04/2004, "País do desperdício", Revista Update, Câmara Americana de Comércio.

Hajeeh, M, Mohammad, O., Behbahani, W., Dashti, B., 2003, A mathematical model for a dual-purpose power and desalination plant, Desalination Vol. 159, pp. 6168 .

Helal, A. M., El-Nashar, A. M., Al-Katheeri, E., AlMalek, S., 2003, Optimal design of hybrid RO-MSF desalination plants. Part I: modeling and algorithms, Desalination Vol. 154, pp. 4366.

Helal, A. M., El-Nashar, A. M., Al-Katheeri, E., AlMalek, S., 2004, Optimal design of hybrid RO-MSF desalination plants. Part II: results and discussions, Desalination Vol. 160, pp. 1327.

Maldonado, J. M. S. V., 1991, Membranas e processos de separação, DEPM/CIM/INT. Rio de Janeiro, Rio de Janeiro.

Morton, A. J., Callister, I. K., Wade, N. M., 1996, Environmental impacts of seawater distillation and reverse osmosis processes, Desalination, Vol. 108, pp. 1-10.

Poulikkas, A., 2001, Optimization algorithm for reverse osmosis desalination economics, Desalination Vol. 133,pp. 7581.

Safi, M. J., Korchani, A., 1999, Cogeneration applied to water desalination: simulation of different technologies, Desalination, Vol. 125, pp. 223229.

Semiat, R., 2000, Desalination: present and future, International Water Resources Association; Water International, Vol. 25, No. 1, pp. 5465.

Silva, A. M., Holanda, M. R, Balestieri, J. A. P., Filho, P. M., 2002, Simuladores para análise de projetos de sistemas de cogeração, Brazilian Congress of Engineering and Thermal Sciences, Proceedings (in CDROM), 7 pp.

Uche, J., Serra, L., Valero, A., 2001, Hybrid desalting systems for avoiding water shortage in Spain, Desalination Vol. 138, pp. 329334;

UNIAGUA. Água no planeta. Available in $<$ www.uniagua.org.br $>$ Access in 10/09/2003.

Van der Bruggen, B., Vandecasteele, C., 2002, Distillation vs membrane filtration: overview process evolutions in seawater desalination, Desalination Vol. 143, pp. 207218;

Verbruggen, A., 1983, Cogeneration- allocation of 